\title{
STRUCTURE OF BONE DISEASE IN DIFFERENT CLINICAL FORMS OF PRIMARY HYPERPARATHYROIDISM
}

\section{Brutskaya-Stempkovskaya E.V., Shepelkevich A.P., Holodova E.A.}

\section{Belarusian State Medical University}

Introduction: Low bone mineral density (BMD) and osteoporosis in PHPT is the result of the acceleration of bone metabolism with overproduction of parathyroid hormone and the rate of resorption exceeds bone formation.

Objective: studying features of bone disease in different clinical variants of PHPT

\section{MATERIALS AND METHODS:}

\section{4 patients with PGPT:}

- 29 fertile women

- 77 postmenopausal women,

- 8 men in the age group up to 50 years;

- indicators of calciumphosphorus metabolism (PTH, $\mathrm{Ca}, \mathrm{Ca} 2+, \mathrm{P})$

- bone markers (alkaline phosphatase, osteocalcin, $\beta$ CTX),

- BMD (Dual-Energy X-ray Absorptiometry)

Zone: $L_{1}-L_{I V}$, neck, upperneck, trochanter, totalhip.

- The control group of 55 patients
RESULTS:

Clinical forms of PHPT

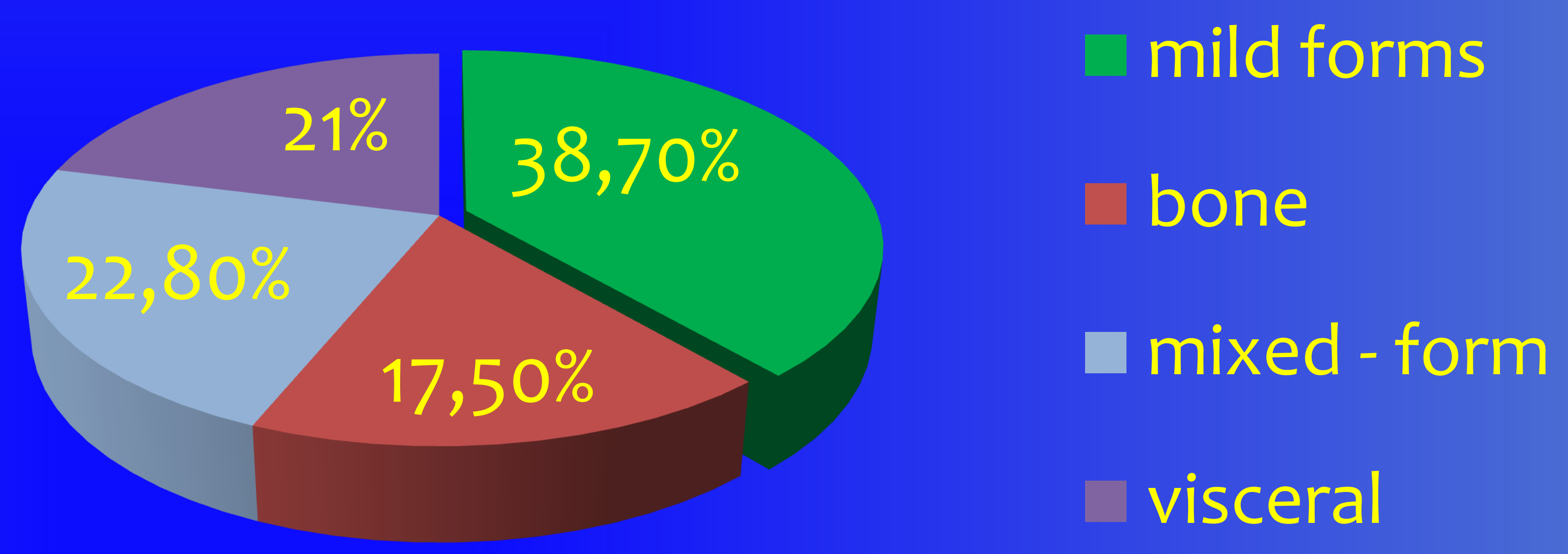

Bone form of PHPT

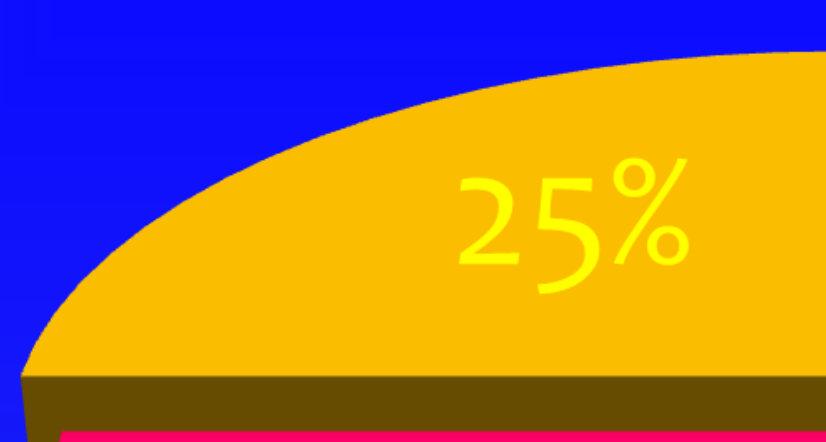

$10 \%$

Recklinghausen's osteodystrophy osteoporosis

osteopenia

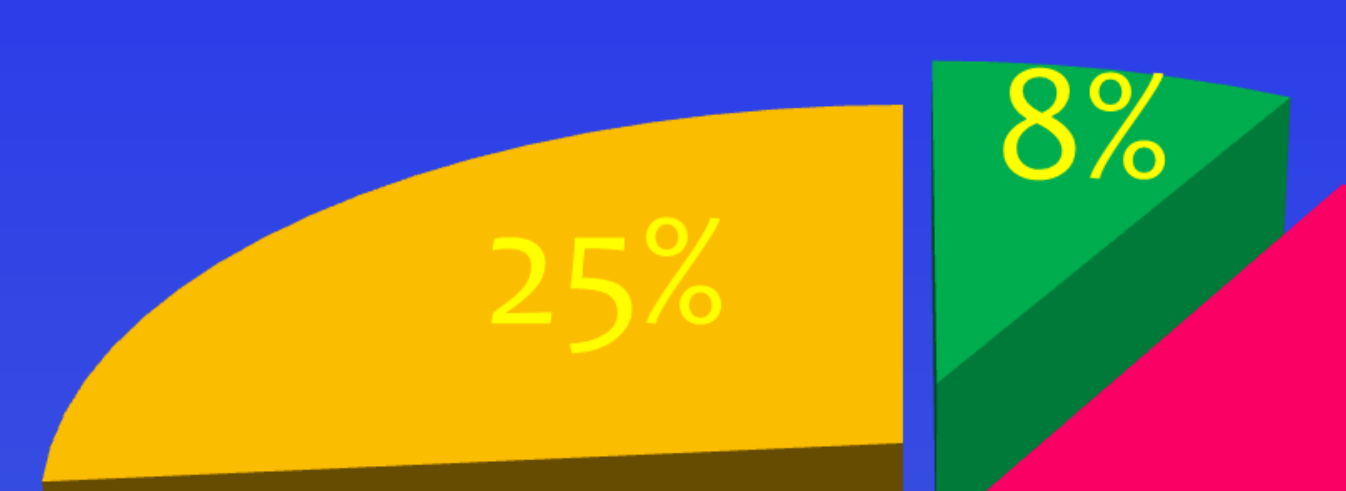

Recklinghausen's osteodystrophy osteoporosis

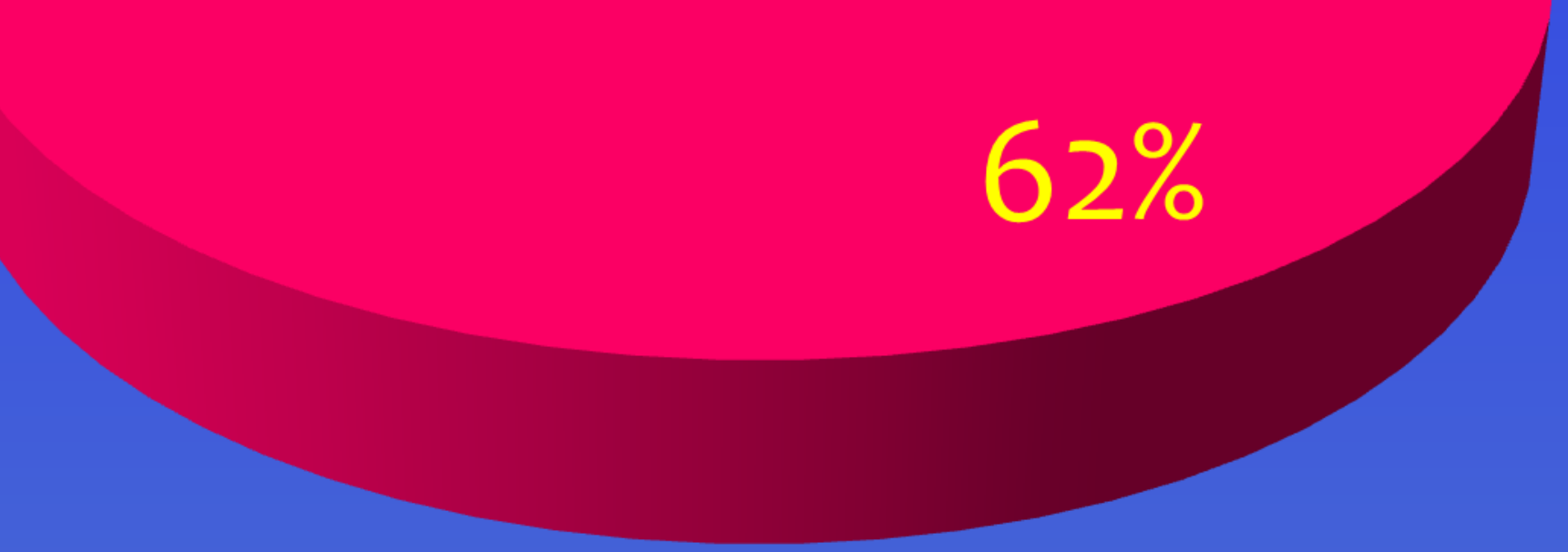

口 osteopenia

\section{CONCLUSION:}

These results suggest a high prevalence of bone disease in patients with manifested forms of primary hyperparathyroidism, and the low frequency of mild forms of PHPT. 